\title{
MEMÓRIAS DO CERRADO: BRINCANDO E APRENDENDO SOBRE A BIODIVERSIDADE E CONSERVAÇÃO DO BIOMA
}

\author{
Ana Carolina de Oliveira Motta ${ }^{1,2}$ \\ Mayara Lustosa de Oliveira Barbosa ${ }^{1,3}$ \\ André Luis da Silva Castro ${ }^{1}$
}

Recibido 05/11/2021 Aceptado 02/12/2021

\section{尊}

O ensino sobre os biomas é uma oportunidade de se trabalhar o contexto dos estudantes a fim de dar sentido aos conteúdos ensinados. Considerando a importância do bioma Cerrado, o presente estudo teve como objetivos desenvolver e avaliar um jogo-didático para o aprendizado e conservação do Cerrado, bem como realizar uma revisão da literatura para fundamentar a elaboração desse recurso. Foi desenvolvido um jogo-didático (Memórias do Cerrado) baseado no tradicional jogo da memória. O jogo foi aplicado em duas escolas e em um grupo escoteiro, totalizando 62 participantes.

$\forall$ Teaching about biomes is an opportunity to work the student's $\$$ context in order to make sense of the contents taught. Considering the importance of the Cerrado biome (Brazilian savannah), this study aimed to develop and evaluate a didactic game for Cerrado learning and conservation, as well as carry out a literature review to support the development of this resource. Therefore, the didactic game "Memórias do Cerrado" (Memories of Brazilian Savanna) was developed, based on the traditional memory game. The game was applied in two schools and in a scout group, totalling 62 participants.

DOI

https://doi.org/10.15366/didacticas2021.25.002

\section{PALABRAS CLAVE}

Jogo da memória, escola, transversal, educação ambiental, ensino, gamificação, ensino os biomas.

1. Programa de Pós-Graduação em Ensino para a Educação Básica, Instituto Federal Goiano, Campus Urutaí, Brasil

2. Instituto Federal de Goiás, Brasil

3. Instituto Federal de Brasília, Brasil

\section{KEYWORDS}

Memory game, school, environmental education, teaching. gamification, teaching of biomes. 


\section{INTRODUÇÃO}

As aprendizagens essenciais definidas para cada etapa da educação básica dependem de ações que envolvam a contextualização dos conteúdos dos componentes curriculares e de formas de exemplificá-los, tornando-os significativos aos estudantes, com base em suas vivências, realidades e do local onde vivem (BRASIL, 2017). Nesse sentido, o bioma no qual a escola está inserida pode ser abordado como parte do contexto de vida dos alunos, uma forma de associar o ensino a aspectos do cotidiano e dar sentido àquilo que se aprende (KATO; KAWASAKI, 2011).

O bioma Cerrado se destaca como contexto de parte significativa da população brasileira, visto que ocupa aproximadamente $24 \%$ do território nacional, abrangendo mais de 10 estados e cerca de 1.500 municípios (BRASIL, 2019). O Cerrado é a savana mais rica em biodiversidade em todo o mundo e é reconhecido, assim como a Mata Atlântica, como uma das áreas mundiais prioritárias para conservação da biodiversidade em razão do elevado número de espécies de plantas e animais endêmicas ameaçadas pelo avanço da ocupação humana (MITTERMEIER; MYERS; MITTERMEIER, 1999).

Estudos indicam, contudo, que a temática Cerrado é ensinada de maneira superficial e é pouco abordada como tema transversal por escolas da região central do Brasil, onde o bioma é predominante (BIZERRIL; FARIA, 2003; BEZERRA; NASCIMENTO, 2015; MOTTA, 2021). Além disso, professores e alunos, em geral, parecem não perceber o Cerrado como o ambiente em que vivem, o que dificulta a compreensão de que seus hábitos afetam o bioma, bem como o entendimento de que o tema deveria permear toda a prática educacional (AMARAL et al., 2017; BORGES; SIMIÃO-FERREIRA, 2018; MOTTA, 2021).

Uma forma de inserir a temática Cerrado na prática educativa é por meio de jogos-didáticos. O uso de jogos como recurso didático torna-se interessante tanto por sua ludicidade, como também por permitir, por meio da criação de uma atmosfera de motivação, a participação ativa dos alunos no processo de ensino-aprendizagem, incorporando experiências, informações e - principalmente - atitudes e valores (HAYDT, 2011). É, sobretudo, na formação de atitudes sociais como cooperação, iniciativa e sensos de responsabilidade social e coletiva, que estão suas maiores contribuições dos jogos como ferramenta de ensino e de sensibilização ambiental.

Em vista disso, tais ferramentas são comumente desenvolvidas e empregadas em ambientes de ensino há muitos anos. Logo, surge o questionamento: o que há de novo nessa proposta? A única forma de direcionar uma proposta educacional inovadora, ainda que utilizando ferramentas convencionais, é analisando o que tem sido feito na área, como os produtos têm sido aplicados, quais têm sido os principais resultados e erros cometidos, de modo a não reproduzir mais do mesmo ou incorrer nas mesmas falhas (TEIXEIRA; NETO, 2012). 
Diante desse cenário, a presente pesquisa teve como objetivos planejar, desenvolver e avaliar um jogo didático para socialização de conceitos relacionados ao bioma Cerrado. Para tanto, na etapa de planejamento houve a realização de uma revisão sistemática da literatura de modo a analisar artigos científicos com resultados da aplicação de metodologias variadas para a promoção da educação ambiental com a temática Cerrado.

Esse tipo de investigação disponibiliza, de acordo com Sampaio e Mancini (2007), um resumo das evidências relacionadas a uma temática específica, mediante a aplicação de métodos explícitos e sistematizados de busca, apreciação crítica e síntese da informação. Ainda segundo as autoras, as revisões sistemáticas possibilitam a incorporação de um espectro maior de resultados relevantes ao viabilizarem, de forma clara e explícita, um resumo das principais conclusões numa determinada área de pesquisa, ao invés de limitar à leitura de somente algumas pesquisas isoladas.

Após esse primeiro momento, e tendo como base os resultados obtidos por meio da revisão, foi desenvolvido e aplicado um jogo, no formato jogo da memória, para três públicos diferentes, visando avaliar a versatilidade do produto nas propostas de aplicação e sua aceitação pelos participantes.

\section{MATERIAIS E MÉTODOS}

\subsection{Caracterização da Pesquisa}

Para alcançar os objetivos acima expostos optou-se pela realização de uma pesquisa descritivo-exploratória, que se caracteriza por descrever e proporcionar maior familiaridade com o objeto de estudo e alguns dos fenômenos a ele associados (GERHARDT; SILVEIRA, 2009). Este estudo visa gerar conhecimentos de aplicação prática e foi baseado na utilização de métodos mistos (mixed methods), integrando aspectos qualitativos e quantitativos para obter uma visão mais abrangente e uma compreensão mais profunda do fenômeno em estudo (CRESWELL, 2007; CASTRO et al., 2010).

\subsection{Parâmetros da Revisão de Literatura}

Para a realização da revisão sistemática de literatura, foram utilizadas cinco bases de dados: Scopus, Web of Science, ERIC, Scielo e Google Scholar. Em todas as bases pesquisou-se pelos descritores selecionados, a saber: ensino e cerrado (teaching and cerrado; ou teaching and brazilian savannah), jogo e cerrado (game and cerrado, ou game and brazilian savannah). Apenas artigos, dissertações e teses que possuíam esses descritores no título, no resumo ou nas palavras-chaves foram considerados para a análise. Tal iniciativa visou eliminar pesquisas tangenciais e que não abordassem de fato o ensino do tema ou a construção e aplicação dos jogos. Trabalhos apresentados em anais de eventos científicos e outras modalidades de publicação não foram considerados. Todos os trabalhos encontrados estavam em inglês, português ou espanhol. 
Foram encontrados 166 trabalhos, dos quais se consideraram 36 após a triagem, sendo: 6 na base Scopus; 1 na Web of Science; 2 na Scielo; 1 na ERIC; 26 na Google Scholar. Os critérios iniciais de exclusão incluíram trabalhos repetidos ou cujos temas não estivessem relacionados aos objetivos da pesquisa, como nos casos em que o termo "cerrado" assumia o significado de "fechado" em língua espanhola. Outro refinamento foi conduzido durante a leitura dos artigos e será exposto na descrição dos resultados. Ressalta-se que não foram excluídos trabalhos do ENPEC (Encontro Nacional de Pesquisa em Ensino de Ciências), por ser um evento nacional de referência na área de ensino de ciências e por possuir realizar avaliação por pares dos trabalhos submetidos.

Os dados tabulados a partir das pesquisas obtidas nas bases foram: título; objetivos; principais resultados e conclusões. Tais dados buscavam responder às seguintes questões: i. quais propostas têm sido apresentadas para ensino de conceitos relacionados ao bioma Cerrado?; ii. quais os objetivos e principais conclusões dos trabalhos? As respostas permitiriam justificar os esforços de nossa pesquisa, além de identificar áreas ainda não cobertas pelos pesquisadores e desenhar uma proposta de intervenção didática mais assertiva.

\subsection{Desenvolvimento da Proposta}

Com base no levantamento realizado, propôs-se o desenvolvimento de um jogo-didático no formato de jogo da memória, cujo aspecto essencialmente visual permite explorar diferentes imagens do Cerrado $(1)^{1}$, como mostra a Figura 1. Assim, é possível complementar eventuais lacunas dos livros didáticos, os quais não costumam priorizar imagens com valor cênico para representar o bioma (BIZERRIL, 2003). O jogo, denominado Memórias do Cerrado, pode ser jogado por somente um ou por vários participantes, sendo viável sua utilização em sala de aula. Quanto maior o número de cartas, maior a quantidade de jogadores possível.

De acordo com Velleman e Warrington (2013), o tradicional jogo da memória se trata de um baralho com uma quantidade " $n$ " de cartas que formam pares idênticos, totalizando " $2 \mathrm{n}$ ". As cartas devem ser embaralhadas e dispostas viradas para baixo. A cada jogada, um dos participantes deve desvirar duas cartas a fim de formar um par. Se as cartas coincidirem, ambas são removidas do jogo e o mesmo jogador repete o lance; se o objetivo não for alcançado, a vez passa a ser de outro participante. Quando todos os pares são removidos, a partida se encerra e aquele que possuir mais cartas vence.

1 Todas as imagens utilizadas na confecção do jogo-didático Memórias do Cerrado apresentam autorização dos autores ou licença livre. As fotografias da capivara e do lobo-guará foram disponibilizadas pelo banco de imagens gratuitas Pixabay e são de autoria de Ana Luísa e Gerhard Gellinger, respectivamente. Já a fotografia do tamanduá-bandeira foi cedida pelo autor, Carlos Augusto Motta. As demais imagens são de autoria de José Augusto Motta. 

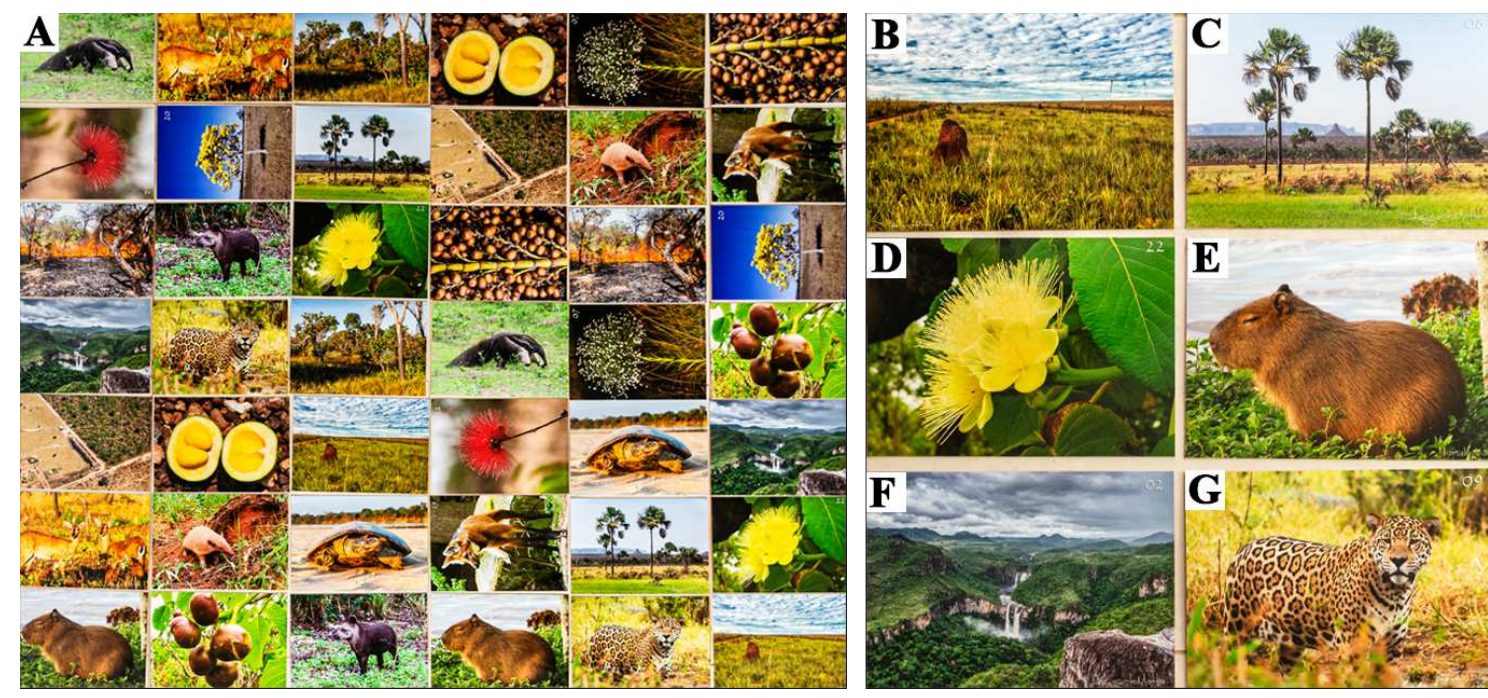

Figura 1. A) Visão geral das cartas do jogo-didático Memória do Cerrado, desenvolvido na presente pesquisa com fotografias da fauna e flora do Cerrado; B) Destaque da carta que ilustra a fitofisionomia "campo limpo"; C) Destaque da carta representativa da fitofisionomia "vereda"; D) Destaque da carta referente à flor do pequizeiro (Caryocar brasiliense); E) Destaque da carta com fotografia da capivara (Hydrochoerus hydrochaeris); F) Destaque da carta com fotografia de paisagem do Parque Nacional da Chapada dos Veadeiros, no estado de Goiás; G) Destaque da carta ilustrativa da onça-pintada (Panthera onca).

No jogo-didático Memórias do Cerrado, a dinâmica descrita por Velleman e Warrington (2013) teve algumas modificações para que o caráter didático fosse intensificado. Nossa versão é composta por 21 pares de imagens, descritas pela Tabela 1, totalizando 42 cartas, confeccionadas em papel fotográfico e papel cartão. A quantidade e o tamanho das cartas, 15 x $21 \mathrm{~cm}$, foram pensados com o intuito de possibilitar a participação simultânea de uma turma com cerca de 20 alunos, dividida em três grupos, cujos membros se revezam a cada jogada. Com um formato maior que o convencional, o baralho pode ser distribuído sobre o chão e os jogadores posicionados ao redor.

Outra característica do Memórias do Cerrado é a possibilidade de ser vinculado a um quiz. Para tanto, todas as imagens são numeradas e apresentam uma questão de múltipla escolha. A imagem da onça-pintada, ilustrada pela Figura 1 letra G, por exemplo, corresponde à questão 9 do quiz (gabarito "b”): “A onça-pintada é um dos animais do Cerrado que estão ameaçados de extinção principalmente por ações como a caça e também: a) Por ser predada por outros animais; b) Pela perda de seu habitat associada principalmente à expansão agrícola, mineração, implantação de hidrelétricas e estradas; c) Captura para apresentação em circos e parques temáticos.”.

Quando o Memórias do Cerrado é jogado com o quiz, o jogador não repete o lance ao conseguir formar um par, como ocorreria na versão tradicional do jogo da memória; em vez disso, sua equipe tem a oportunidade de responder a uma questão do quiz e pontuar novamente em caso de acerto. Se o jogo for aplicado sem o quiz, o mediador deve sociali- 
zar as informações sobre as imagens sempre que a carta for virada pela primeira vez. $\mathrm{O}$ quiz pode ser usado tanto para uma revisão de conteúdo como para deixar a partida mais desafiadora. Desafios são usados para criar diferentes níveis de dificuldade no jogo com o objetivo de incentivar a diversão e motivar o participante a passar mais tempo jogando (EZZIYYANI, 2019). Por esse motivo, tal proposta de gamificação foi inserida em uma das aplicações que realizamos e será descrita em nossos resultados.

\begin{tabular}{|c|c|c|}
\hline FAUNA & FLORA & PAISAGEM \\
\hline $\begin{array}{c}\text { Anta } \\
\text { (Tapirus terrestris) }\end{array}$ & $\begin{array}{c}\text { Buriti } \\
\text { (Mauritia flexuosa) }\end{array}$ & $\begin{array}{c}\text { Área desmatada por carvoaria } \\
\text { (Niquelândia-GO) }\end{array}$ \\
\hline $\begin{array}{c}\text { Capivara } \\
\text { (Hydrochoerus hydrochaeris) }\end{array}$ & $\begin{array}{c}\text { Caliandra } \\
\text { (Calliandra dysantha) }\end{array}$ & $\begin{array}{c}\text { Cachoeira } \\
\text { (Parque Nacional da Chapada dos } \\
\text { Veadeiros, Alto Paraíso-GO) }\end{array}$ \\
\hline $\begin{array}{l}\text { Lobo-guará } \\
\text { (Chrysocyon brachyurus) }\end{array}$ & $\begin{array}{c}\text { Chuveirinho } \\
\text { (Paepalanthus sp) }\end{array}$ & $\begin{array}{l}\text { Campo limpo } \\
\text { (Parque Nacional das Emas, } \\
\text { Mineiros-G0) }\end{array}$ \\
\hline $\begin{array}{c}\text { Onça pintada } \\
\text { (Panthera onca) }\end{array}$ & $\begin{array}{c}\text { Ipê amarelo } \\
\text { (Tabebuia chrysotricha) }\end{array}$ & $\begin{array}{l}\text { Cerrado stricto sensu } \\
\text { (RESEX Lago do Cedro, Aruanã- } \\
\text { GO) }\end{array}$ \\
\hline $\begin{array}{l}\text { Tamanduá-bandeira } \\
\text { (Myrmecophaga tridactyla) }\end{array}$ & $\begin{array}{l}\text { Fruto do pequi aberto } \\
\text { (Caryocar brasiliense) }\end{array}$ & $\begin{array}{c}\text { Queimada } \\
\text { (São Domingos-GO) }\end{array}$ \\
\hline $\begin{array}{l}\text { Tartaruga-da-Amazônia } \\
\text { (Podocnemis expansa) }\end{array}$ & $\begin{array}{l}\text { Pequizeiro com frutos } \\
\text { (Caryocar brasiliense) }\end{array}$ & $\begin{array}{c}\text { Veredas } \\
\text { (São Domingos-GO) }\end{array}$ \\
\hline $\begin{array}{c}\text { Tatu peba } \\
\text { (Euphractus sexcinctus) }\end{array}$ & $\begin{array}{l}\text { Flores do pequizeiro } \\
\text { (Caryocar brasiliense) }\end{array}$ & \\
\hline $\begin{array}{c}\text { Veado-campeiro } \\
\text { (Ozotoceros bezoarticus) }\end{array}$ & & \\
\hline
\end{tabular}

Tabela 1. Elementos da biodiversidade do Cerrado abordados o no jogo Cerrado em Dobro, contendo 21 pares de imagens.

\subsection{Público-alvo}

De modo a obter aplicações variadas e identificar as potencialidades do jogo-didático Memórias do Cerrado, esta pesquisa foi concebida por meio de três experiências, ocorridas em duas instituições de educação formal, bem como em uma instituição de educação não formal (GOHN, 2009). A amostra, apresentada na tabela 2, totalizou 62 sujeitos, divididos em três grupos: o primeiro de uma escola da rede privada de educação (G1); o segundo de uma escola da rede estadual de educação (G2); o terceiro de um grupo escoteiro (G3). 


\begin{tabular}{|c|c|c|c|c|c|c|}
\hline & $\begin{array}{l}\text { Tipo de } \\
\text { Educação }\end{array}$ & Local & Público-alvo & $\begin{array}{l}\text { Formato do } \\
\text { jogo }\end{array}$ & Mediadores & $\begin{array}{l}\text { Método de } \\
\text { avaliação }\end{array}$ \\
\hline G1 & formal & $\begin{array}{c}\text { Escola da rede priva- } \\
\text { da (Aparecida de } \\
\text { Goiânia-GO) }\end{array}$ & $\begin{array}{l}21 \text { alunos, de } \\
11 \text { a } 13 \text { anos, } \\
\text { 7o ano }\end{array}$ & $\begin{array}{c}\text { jogo da me- } \\
\text { mória } \\
+ \\
\text { quiz }\end{array}$ & $\begin{array}{c}\text { professora de } \\
\text { Geografia + } \\
\text { pesquisadora }\end{array}$ & $\begin{array}{c}\text { questionário } \\
+ \\
\text { pesquisa de } \\
\text { opinião }\end{array}$ \\
\hline $\mathrm{G} 2$ & formal & $\begin{array}{c}\text { Escola da rede esta- } \\
\text { dual de educação } \\
\text { (Aparecida de Goiâ- } \\
\text { nia-GO) }\end{array}$ & $\begin{array}{l}20 \text { alunos, de } \\
11 \text { a } 15 \text { anos, } \\
7 \text { o ano }\end{array}$ & $\begin{array}{l}\text { jogo da me- } \\
\text { mória }\end{array}$ & $\begin{array}{c}\text { professora de } \\
\text { Geografia + } \\
\text { pesquisadora }\end{array}$ & $\begin{array}{c}\text { ilustrações + } \\
\text { pesquisa de } \\
\text { opinião }\end{array}$ \\
\hline G3 & não formal & $\begin{array}{l}\text { Grupo escoteiro } \\
\text { (Goiânia-GO) }\end{array}$ & $\begin{array}{l}21 \text { crianças, } \\
\text { de } 7 \text { a } 10 \text { anos }\end{array}$ & $\begin{array}{l}\text { jogo da me- } \\
\text { mória }\end{array}$ & $\begin{array}{l}\text { educadores vo- } \\
\text { luntários do } \\
\text { grupo escoteiro }\end{array}$ & $\begin{array}{l}\text { observação } \\
\text { participante }\end{array}$ \\
\hline
\end{tabular}

Tabela 2. Participantes do estudo, tipo de educação, local, formato do jogo, mediador e métodos de avaliação utilizados.

Presente em mais de 200 países e com cerca 40 milhões de membros, o escotismo é um movimento educacional que incentiva crianças e jovens a assumirem seu próprio desenvolvimento e a se envolverem com a comunidade (ESCOTEIROS DO BRASIL, 2019). Experiências derivadas do escotismo podem facilitar a compreensão futura de conteúdos em ambientes formais, uma vez que ideias científicas encontradas no currículo escolar aparecem com frequência em atividades escoteiras (JARMAN, 2012).

Nas instituições de educação formal, as atividades foram realizadas com o apoio da professora de Geografia que leciona para ambos os grupos. Embora a docente fosse a mesma, o conhecimento dos alunos sobre o Cerrado diferia: o conteúdo sobre o bioma proposto para a disciplina no $7^{\circ}$ ano já havia sido ministrado para o G1, enquanto que, para o G2, seria lecionado no segundo semestre. Esse fator foi determinante na escolha das escolas, uma vez que possibilita a utilização de diferentes metodologias na aplicação, bem como na avaliação do jogo didático. Já na instituição de educação não formal, o grupo escoteiro, a atividade contou com o apoio de educadores membros do grupo.

\subsection{Instrumentos aplicados para levantamento e análise dos dados}

Com o objetivo de avaliar o potencial do Memórias do Cerrado como produto educacional, a coleta de dados dos participantes se deu por meio de diferentes instrumentos, observando as idiossincrasias de cada grupo: desenho, questionário, pesquisa de opinião e observação participante. Embora nosso recurso didático não tenha aspectos inovadores em essência, o presente artigo apresenta uma estrutura consolidada de pesquisa para a elaboração de materiais didáticos fundamentados em trabalhos anteriormente produzidos. Além disso, nenhuma das bases pesquisadas possui um artigo com a estrutura aqui sugerida, ressaltando o ineditismo da proposta. 


\section{a) Desenhos - pré-teste e pós-teste}

$\mathrm{O}$ ato de desenhar cria relações e revela conceitos (GOLDBERG; YUNES; FREITAS, 2005), possibilita a expressão das percepções dos sujeitos, mesmo que esses não apresentem conhecimentos formais sobre determinado assunto. O desenho, portanto, foi adotado para avaliar o ganho de conhecimento pelo G2, que embora integre a educação formal, ainda não estudara o tema no $7^{\circ}$ ano.

Antes da aplicação do jogo foi solicitado aos alunos que desenhassem, individualmente, uma paisagem que representasse suas percepções pessoais sobre o Cerrado. Após a partida, pedimos que repetissem a ilustração incluindo elementos apresentados ao longo da atividade. Associadas às ilustrações, foram realizadas breves entrevistas para a identificação dos elementos desenhados e coleta de dados de caracterização dos sujeitos.

Tal proposta foi planejada de modo a avaliar a aquisição de conhecimentos de forma mais lúdica e acessível. A análise dos desenhos foi realizada a partir do número de elementos da fauna e da flora do Cerrado desenhados pelos estudantes antes (pré-teste) de e após (pós-teste) jogarem Memórias do Cerrado. As frequências foram comparadas por teste $t$ de Student para amostras pareadas, no software livre Bioestat, adotando como nível de significância 5\%, após verificação de normalidade pelo teste de Shapiro-Wilk.

\section{b) Questionário - pré-teste e pós-teste}

O questionário foi elaborado conforme o conteúdo sobre o Cerrado proposto para o $7^{\circ}$ ano do ensino fundamental (educação formal) e abordado pelo Memórias do Cerrado. As questões demandavam conhecimento das principais causas da degradação do bioma, sua diversidade biológica, sua importância social e hídrica, e a abundância de espécies endêmicas. Portanto, embora o questionário pudesse oferecer maior agilidade e menor custo no levantamento dos dados (GIL, 2002), a ferramenta foi utilizada, por coerência, somente com o G1, cujo plano de aulas contemplara o tema à época da presente pesquisa.

Antes do início do jogo (pré-teste) e após sua conclusão (pós-teste), os participantes do G1 responderam a um mesmo questionário, composto por cinco questões de múltipla escolha e quatro alternativas cada, sendo apenas uma correta. As frequências de acertos do pré e pós-teste foram comparadas por teste $t$ de Student, seguindo o mesmo padrão aplicado à análise dos dados obtidos com os desenhos.

\section{c) Observação participante}

A observação participante é uma abordagem em que se obtêm informações por meio da interação com os sujeitos da pesquisa, envolvendo observação direta, conversas informais, entrevistas e experiências pessoais (LEVINE et al., 2009). Esse método foi proposto por possibilitar, quando associado a outros instrumentos de coleta de dados, uma visão abrangente dos participantes, não reduzindo a análise a seus desempenhos nos testes. 
Por meio da observação participante, buscamos identificar no G3 o interesse pelo jogo, a competitividade, o engajamento e a colaboração entre os participantes. Para tanto, um dos mediadores adotou um diário de campo, no qual foram descritos os comportamentos individuais e coletivos nas aplicações do jogo-didático, assim como toda informação considerada relevante. Essa foi a única ferramenta de avaliação utilizada com G3 devido ao tempo disponibilizado para a realização da atividade.

\section{d) Pesquisa de opinião}

A opinião dos sujeitos a respeito do produto educacional é importante para avaliá-lo enquanto ferramenta auxiliar no processo de ensino-aprendizagem e para indicar possíveis adequações, se necessário. Por esse motivo, foi utilizado um formulário fundamentado na escala Likert para verificar as impressões dos participantes diante da proposta.

Tal método foi desenvolvido por Likert (1932) para o levantamento de dados em pesquisas direcionadas à identificação das atitudes dos sujeitos, ou seja, suas expressões, sentimentos, opiniões ou intenções. Trata-se de afirmações para as quais o participante deve marcar uma das respostas possíveis, que variam de muito negativas a muito positivas.

Aplicado aos participantes do G1 e do G2, o formulário da presente pesquisa dispôs de seis sentenças afirmativas e uma negativa, que dizia "O jogo não foi útil para o meu aprendizado". As possíveis respostas foram formuladas em linguagem coloquial ("nem um pouco"; "não"; "não sei”; "sim”; "com certeza”) e apresentavam ícones ilustrativos (emoticons) para uma rápida compreensão.

\section{RESULTADOS E DISCUSSÃO}

\subsection{Resultados da revisão sistemática de literatura}

O Quadro 1 apresenta os principais aspectos abordados nos 49 trabalhos encontrados. A base Scopus apresentou seis dessas publicações, cujos objetivos estavam centrados nos seguintes tópicos principais: 1) análise ou proposição de situações didáticas voltadas para a educação ambiental, a saber: plantio de mudas, coleta de lixo, palestra, reciclagem, projetos ambientais, caminhadas orientadas em trilhas interpretativas ou convencionais, para ensino de ecologia e botânica, bem como amostragem de insetos aquáticos e identificação ao microscópio (ARRUDA; FARIAS; GARBOUJ, 2018; RISSI; CAVASSAN, 2013; ANGELINI et al., 2011); 2) análise da relação entre educação ambiental e estudos culturais, tendo como base narrativas televisivas do programa "Repórter Eco", cujo foco era o manejo sustentável do baru, árvore típica do Cerrado (BELINASO; ESTEVINHO; RAMOS, 2018); 3) descrever e analisar a importância da produção científica dos cursos de pós-graduação para o desenvolvimento da ornitologia no Brasil (BORGES, 2008); 4) ana- 
lisar, sob a ótica da etnozoologia, os conhecimentos e os possíveis usos da fauna pelos moradores da Serra do Ouro Branco - MG (PINTO; MATEUS; PIRES, 2012).

Embora relacionados ao ensino, alguns trabalhos apenas tangenciam a temática de estudo da presente pesquisa (BELINASO; ESTEVINHO; RAMOS, 2018; BORGES, 2008; PINTO; MATEUS; PIRES, 2012). Assim, com relação às conclusões mais relevantes para nosso trabalho, podemos citar que estratégias de ensino diferenciadas promovem o desencadeamento de experiências futuras favoráveis com o bioma e contribuem positivamente para a construção do conhecimento dos alunos e suas formas de socializar os conteúdos explorados no Cerrado (ARRUDA; FARIAS; GARBOUJ, 2018; RISSI; CAVASSAN, 2013).

Vale destacar o trabalho de Angelini e colaboradores (2011), no qual é possível verificar que, em trabalhos ao ar livre, a orientação oral dos instrutores é mais eficaz que o uso de manuais, possivelmente porque o processo de ensino é quase sempre fornecido pelo professor. O trabalho também faz uso da análise de testes antes e depois da aplicação de atividades. Ambas as estratégias foram utilizadas no momento da aplicação de nossa proposta.

O resultado encontrado na Web of Science se trata de um estudo que buscou investigar as concepções que estudantes do ensino fundamental têm a respeito do bioma Cerrado (BEZERRA; NASCIMENTO, 2015). Na pesquisa, feita por meio de um questionário semiestruturado respondido por 156 estudantes, percebeu-se pouco entendimento destes sobre as características do solo, da paisagem e da flora do Cerrado. Os conceitos muitas vezes estavam reduzidos apenas a informações tradicionalmente difundidas em livros didáticos. Os autores apresentam então, a necessidade de abordar o tema Cerrado no Ensino Fundamental de maneira mais detida e contextualizada, bem como a utilização de recursos didáticos diferenciados para facilitar a aprendizagem mais efetiva das características desse importante bioma nacional (BEZERRA; NASCIMENTO, 2015).

Tais conclusões fortalecem e justificam nossos intentos, ademais, também serviram como direcionador, no sentido de adicionar aspectos relacionados à flora e paisagem do Cerrado no recurso didático. Outro ponto a ser destacado é o fato de que a pesquisa foi realizada no interior do estado de Goiás, região próxima à de aplicação da presente pesquisa, demonstrando que muitas crianças em idade escolar não compreendem a importância do bioma no qual estão inseridas.

Com relação à base Scielo, os dois trabalhos analisados eram bastante específicos e centravam seus objetivos nos seguintes pontos: 1) adequar um protocolo de avaliação rápida de rios para utilização por estudantes do ensino fundamental em riachos do sudeste goiano (GUIMARÃES; RODRIGUES; MALAFAIA, 2012); 2) despertar um olhar críticoambiental em estudantes, por meio da construção de uma trilha ecológica no Cerrado, visando a integração do ambiente natural e urbano (CAZOTO; TOZONI-REIS, 2008). Embora sejam bem específicos, as conclusões demonstram que ambos os recursos alcança- 
ram seu objetivo de promover a interação comunidade-ambiente, e articular a consciência ambiental às ações educativas.

Situações didáticas voltadas para a educação ambiental, a saber: plantio de mudas, coleta de lixo, palestra, reciclagem, projetos ambientais, caminhadas orientadas em trilhas interpretativas ou convencionais, para ensino de ecologia e botânica, bem como amostragem de insetos aquáticos e identificação ao microscópio.

Arruda, Farias e Garbouj, 2018; Rissi e Cavassan, 2013; Angelini et al., 2011.

Relação entre educação ambiental e estudos culturais, tendo como base narrativas televisas do programa "Repórter Eco" a respeito do manejo sustentável do baru.

A importância da produção científica dos cursos de pós-graduação para o desenvolvimento da ornitologia no Brasil.

Conhecimentos e os possíveis usos da fauna pelos moradores da Serra do Ouro Branco - MG, sob a ótica da etnozoologia.

Concepções que estudantes do Ensino Fundamental têm a respeito do bioma Cerrado.

Adequação de um protocolo de avaliação rápida de rios para utilização por estudantes do ensino fundamental em riachos do sudeste goiano.

0 despertar um olhar crítico-ambiental em estudantes, por meio da construção de uma trilha ecológica no Cerrado, visando à integração do ambiente natural e urbano.

A falta de atenção a uma dimensão estética na prática e pesquisa em educação ambiental.

enfoque do tema Cerrado dado no Ensino Fundamental, assim como o grau de informação dos estudantes deste nível ou do Ensino Médio sobre o bioma e sua conservação, em escolas públicas e particulares.

Abordagem do bioma Cerrado em documentos oficiais, no currículo e em livros didáticos de biologia destinados ao Ensino Médio e Fundamental.

A aquisição de conhecimento, as atitudes, os valores, assim como o processo de aprendizagem sobre o bioma Cerrado pela interação dos alunos em aula, pelo uso de espaços não formais ou pela avaliação do uso de metodologias diferenciadas.

Atuação, compreensão e escolha de procedimentos didáticos por parte dos docentes sobre o bioma Cerrado, ou formar, em nível inicial e continuado, professores e pesquisadores capazes de elaborar recursos para o ensino da temática.

Contribuições da Educação Ambiental para práticas sustentáveis do agronegócio no Cerrado.
Borges, 2008.

Pinto et al., 2012.

Bezerra e Nascimento, 2015.

Guimarães, Rodrigues e Malafaia, 2012.

Cazoto e Tozoni-Reis, 2008.

lared, Oliveira e Reid, 2017.

Bizerril e Faria, 2003;

Costa et al., 2011;

Palhaci et al., 2009;

Borges e Simião-Ferreira, 2018;

Queiroz, Pereira e Borges, 2013;

Martins e Brando, 2009; Amaral et al., 2017.

Bezerra, Suess e Capelle, 2013; Costa et al., 2011;

Santos, 2017 . França, 2019.

Kanda et al., 2014; Oliveira, 2012; Castro, 2009; Barbosa, 2018;

Faleiro et al., 2009; Rosa, 2015; Neto e Souza, 2017; Rodrigues, 2019; Gonçalvez, 2015.

Seniciato, Cavassan, 2009; Brando, 2010; Vallerius, 2015; Francelin, 2011.

Oliveira, 2014.

Quadro 1. Resultados da revisão sistemática sobre Cerrado, Ensino e Jogos 
$\mathrm{Na}$ base ERIC, o artigo encontrado abordou a falta de atenção a uma dimensão estética na prática e pesquisa em educação ambiental (IARED; OLIVEIRA; REID, 2017). Associadas a imagens do Cerrado, os autores trouxeram questões temáticas, tais como: quais aspectos da experiência estética são trazidos à atenção nesse tipo de vegetação? Quais percepções o Cerrado evoca? Quais sentimentos e emoções são despertados? Os autores ressaltam o baixo valor estético atribuído ao Cerrado, muito provavelmente em função de como o bioma tem sido representado em livros didáticos, os quais são, muitas vezes, a única fonte de representação das paisagens para os estudantes. Em concordância com o exposto, segundo Bizerril (2004), a biodiversidade do Cerrado dificilmente é abordada no currículo escolar, refletindo o baixo valor estético colocado neste tipo de vegetação.

Outro aspecto abordado pela pesquisa é o papel do educador ou mediador das propostas de educação ambiental. Os autores afirmam que é tarefa de educadores e pesquisadores ambientais críticos: fomentar a curiosidade, o respeito e a admiração por todos os seres do ambiente estudado, assim como buscar a reflexão sobre "qual currículo estamos propondo? Qual conteúdo experiencial e modos estamos priorizando?”. Seguindo essa linha de argumentos e reflexões, foi estabelecida a ideia de uso de imagens que evocassem uma sensação estética mais positiva em relação ao Cerrado, assim como inserir aspectos lúdicos na metodologia e abordar espécies variadas (flores, animais) e paisagens típicas, de modo a impedir a consolidação de ideias estereotipadas a respeito do bioma como um ambiente seco e com pouca vida.

Na última base de dados analisada (Google Scholar) foi encontrado um maior número de trabalhos, entretanto, muitos deles eram monografias ou resumos apresentados em congressos. Os objetivos das pesquisas analisadas estavam centrados nas seguintes intenções: 1) avaliar o enfoque do tema Cerrado dado no ensino fundamental, assim como o grau de informação dos estudantes deste nível ou do Ensino Médio sobre o bioma e sua conservação, em escolas públicas e particulares (BIZERRIL; FARIA, 2003; COSTA et al., 2011; PALHACI et al., 2009; BORGES; SIMIÃO-FERREIRA, 2018; QUEIROZ; PEREIRA; BORGES, 2013; MARTINS; BRANDO, 2009; AMARAL et al., 2017).; 2) analisar como ocorre a abordagem do bioma Cerrado em documentos oficiais, no currículo e em livros didáticos de biologia destinados ao Ensino Médio e Fundamental (BEZERRA; SUESS, 2013; COSTA et al., 2011; SANTOS, 2017; FRANÇA, 2019); 3) verificar aquisição de conhecimento, atitudes, valores, assim como o processo de aprendizagem sobre o bioma cerrado pela interação dos alunos em aula, pelo uso de espaços não formais ou pela avaliação do uso de metodologias diferenciadas (KANDA et al., 2014; OLIVEIRA, 2012; CASTRO, 2009; BARBOSA, 2018; FALEIRO et al., 2009; ROSA, 2015; NETO; SOUZA, 2017; RODRIGUES, 2019; GONÇALVES, 2015); 4) analisar a atuação, compreensão e escolha de procedimentos didáticos por parte dos docentes sobre o bioma Cerrado, ou formar, em nível inicial e continuado, professores e pesquisadores capazes de elaborar recursos para o ensino da temática, (SENICIATO; CAVASSAN, 2009; BRANDO, 2010; VA- 
LLERIUS, 2015; FRANCELIN, 2011); e 5) analisar contribuições da Educação Ambiental para práticas sustentáveis do agronegócio no Cerrado (OLIVEIRA, 2014).

Com relação às conclusões mais relevantes, Palhaci et al. (2009), revelam como fator negativo que a maioria dos alunos não soube responder as perguntas do questionário e concluem ser necessário maior contextualização no ensino sobre o Cerrado, de modo a provocar no aluno um maior interesse e respeito pelo ambiente em que vive. Nessa linha, Vallerius (2015), destaca o relativo desinteresse por parte dos alunos na temática Cerrado e a pouca motivação dos professores para trabalhar com as questões a ele relacionadas. Queiroz, Pereira e Borges, (2013) corroboram as pontuações e complementam reforçando que os professores se encontram desinteressados em abordar o tema cerrado em sala de aula, devido à falta de recursos ou de informação do educador sobre o tema.

Indo ao encontro das afirmações, Seniciato, Cavassan (2009) e Bizerril e Faria (2003) afirmam em suas conclusões, que é preciso auxiliar os futuros professores na construção de significados, sejam eles científicos ou estéticos, sobre o cerrado, já que o bioma parece pouco conhecido e valorizado por parte significativa dos docentes e pelas escolas de um modo geral. Nesse sentido, é de extrema importância o desenvolvimento de recursos didáticos práticos, atrativos e representativos, de modo que seja possível tratar o assunto com os estudantes.

Bizerril e Faria (2003) concluem que as razões apontadas pelos professores para a fraca atuação da escola em relação ao Cerrado são ligadas a lacunas na própria formação inicial e à abordagem dada pela mídia ao bioma, o que leva a crer que é necessário investir-se "em caráter de urgência, na sensibilização e divulgação do Cerrado" de modo a as segurar o comprometimento social com a preservação do bioma.

Quanto à análise dos livros didáticos, essa revelou que o Cerrado é muitas vezes tratado de maneira acrítica quanto à sua situação de degradação e importância para a manutenção da biodiversidade (BEZERRA; SUESS, 2013), com a apresentação de figuras escassas, pequenas e pouco detalhadas (PALHACI et al., 2009). Além disso, são destacados aspectos da agropecuária, produtividade e uma visão positiva do crescimento econômico em detrimento da conservação do bioma (COSTA et al., 2011).

Sobre o uso de metodologias diferenciadas, Kanda (2014), reforça que a adoção de novas metodologias de ensino que fujam do tradicionalismo, criando oportunidades que facilitem a aprendizagem, deve ser incentivada. Faleiro e colaboradores (2009) corroboram as afirmações e pontuam que jogos e outras metodologias variadas, são importantes abordagens educacionais, as quais podem propiciar melhor exploração de temáticas na área da Educação Ambiental.

As análises das pesquisas acima pontuadas compuseram o momento de planejamento e a pesquisa de campo para o desenvolvimento de um recurso didático, o jogo da memória. $\mathrm{O}$ intento dos pesquisadores era produzir um recurso que permitisse uma aplicação ampla (para idades variadas), em ambientes formais ou não formais, e com uma repre- 
sentação adequada do bioma Cerrado, associando conhecimentos científicos e os aspectos estéticos positivos associados ao bioma.

Muitas escolas não têm condições de levar estudantes para trilhas ou outros ambientes em meio ao Cerrado, não somente pelos custos no transporte, como pelo fato de o professor ser apenas um no comando de muitos estudantes. Assim, como seria possível levar imagens de uma paisagem real do Cerrado, desmistificando a ideia consolidada de um ambiente com pouca biodiversidade? O jogo da memória é um recurso barato, de aplicação fácil e intuitiva, e com o potencial intrínseco de evocar na mente das crianças e jovens outro tipo de sensação com relação a esse ambiente. Além disso, se combinado com questões específicas dos temas ilustrados nas imagens, pode promover um envolvimento coletivo e um aprofundamento mais adequado ao tema em estudo.

\subsection{Resultados das aplicações do jogo Memórias do Cerrado}

A avaliação do jogo-didático ocorreu por meio de três experiências, com métodos quantitativos e qualitativos, que visavam avaliar o conhecimento (desenhos e questionários), o comportamento (observação participante) e a opinião (questionário de opinião) dos sujeitos. Cada um desses métodos levou a resultados complementares, que serão apresentados e discutidos a seguir.

Os resultados do pré e pós-teste com os desenhos revelaram, perante análises estatísticas, aumento no número de elementos desenhados após a utilização do jogo pelo G2 (teste $\mathrm{t}$ para amostras pareadas, $\mathrm{t}=-3,74, \mathrm{GL}=19, \mathrm{p}<0,001$ ), conforme a Figura 2 .

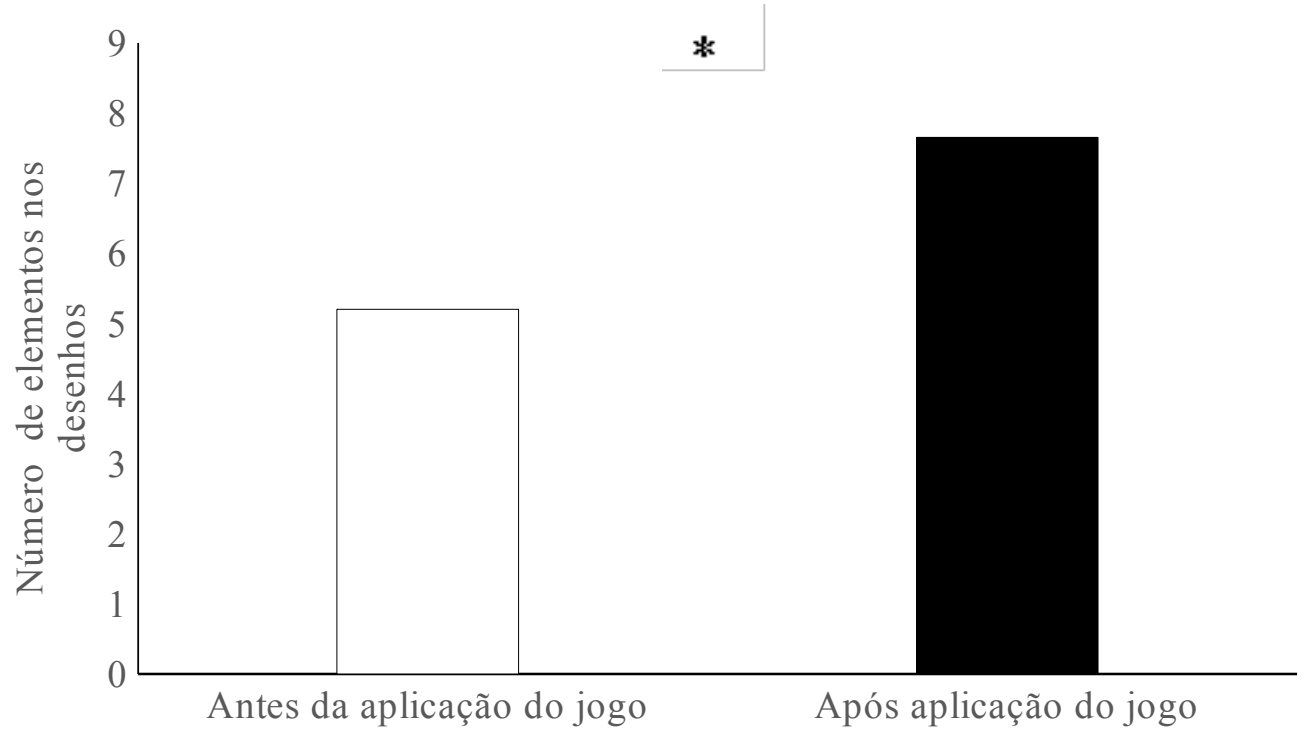

Figura 2. Média \pm desvio padrão do número de elementos nos desenhos dos participantes da pesquisa, integrantes do G2, antes e após a aplicação do jogo Memória do Cerrado ( $n=20$, teste $t$ para amostras pareadas, $\left.\mathrm{t}=-3,74, \mathrm{GL}=19,{ }^{*} \mathrm{p}<0,001\right)$. 
A proposta de realização de desenhos segue também a sugestão presente no trabalho de Borges e Simião-Ferreira (2018), analisado durante a revisão sistemática de literatura. Os autores afirmam que não tem sido muito comum trabalhos utilizarem desenhos para avaliar representações do meio ambiente e sua biodiversidade, e reforçam que, de modo geral, a criança gosta de desenhar, sendo este um importante veículo de expressão, por meio do qual ela pode exteriorizar a percepção de conceitos.

É possível inferir que essas particularidades do desenho podem ter contribuído para que os alunos se sentissem menos pressionados diante de uma avaliação, conforme observamos nos comportamentos do G2 durante os testes. Os alunos, em sua maioria, não demonstraram apreensão e pareceram se divertir enquanto desenhavam. O desenho como ferramenta de avaliação, entretanto, é limitado na aferição de conhecimentos mais específicos, tendo sido necessária a utilização de um questionário para avaliar o jogo-didático em sua forma completa: jogo da memória e quiz.

A análise estatística dos acertos no questionário, respondido pelo G1, também revelou melhora no desempenho desse grupo no pós-teste em relação ao pré-teste (teste $t$ para amostras pareadas, $\mathrm{t}=-5,77, \mathrm{GL}=19, \mathrm{p}<0,0001)$, conforme a figura 3 . Esse resultado, bem como o do G2, pode estar relacionado ao apelo motivacional do jogo. Ao comparar a motivação de alunos diante de duas atividades distintas, uma baseada em exercícios de repetição e outra em um jogo, Malone e Lepper (1987, pág. 227) identificaram um maior apelo motivacional do jogo.

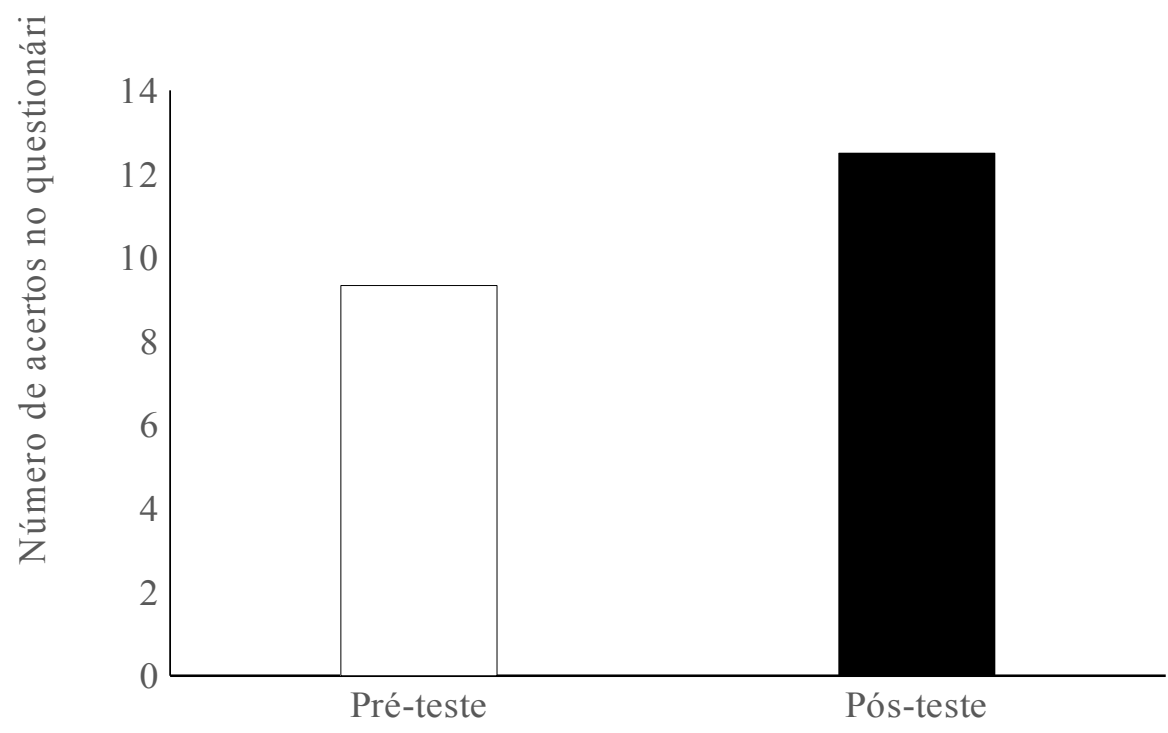

Figura 3. Média \pm desvio padrão do número de acertos de perguntas do questionário dos participantes da pesquisa, integrantes do G1, antes da aplicação do jogo (pré-teste) e após a aplicação do jogo (pós-teste) $(n=20$, teste $t$ para amostras pareadas, $t=-5,77, G L=19, p<0,0001)$. 
Mesmo atividades que não sejam intrinsecamente motivadoras podem, segundo Malone e Lepper (1987), ser aprimoradas a partir de uma série de motivações. Dentre elas, motivações individuais como curiosidade e desafio, e interpessoais como competitividade e cooperação, foram observadas nos sujeitos da presente pesquisa, por meio da observação participante. Todos os grupos mostraram-se bastante curiosos, buscando conversar com a pesquisadora sobre o estudo e o jogo-didático, antes mesmo que seu formato e sua dinâmica fossem revelados.

A mudança de ambiente para a aplicação do Memórias do Cerrado também pareceu aguçar a curiosidade dos participantes. O G1 foi levado para a biblioteca da escola, enquanto o G2 foi para o pátio, e o G3, para uma fazenda. Esses espaços possibilitaram que as cartas fossem dispostas sobre o solo ou sobre uma mesa ampla, e que os participantes se posicionassem ao redor, divididos em equipes de sete participantes.

O trabalho em equipe, a memorização e o raciocínio rápido, sob pressão, são alguns desafios propostos por nosso jogo-didático. Na experiência com o G1, que envolveu o quiz, os participantes mostraram-se mais desafiados e competitivos, e um deles, em particular, demonstrou certa dificuldade nesse aspecto. Embora extremamente inteligente, o aluno permaneceu apreensivo diante do quiz: com a cabeça baixa, pousada sobre as mãos, pensava as respostas sem discutir com sua equipe, que apostava totalmente em seus conhecimentos com expectativa e ansiedade. Após a partida, o aluno isolou-se dos demais, frustrado com o próprio desempenho.

A inteligência emocional é necessária para que o intelecto opere de forma mais eficiente (GOLEMAN, 1995). Conforme observamos nas experiências com os três grupos, as equipes que tiveram melhor desempenho souberam aliar conhecimento, competitividade e cooperação entre os membros, que entravam em acordo antes de qualquer jogada ou resposta ao quiz. Para Antunes (2012, p. 126), "o sucesso de qualquer grupo exige a coesão e não se fundamenta a coesão sem solidariedade, ainda que para o desafio de superar o outro".

Os participantes do G3, embora mais jovens que os dos demais grupos, lidaram bem com as emoções e demonstraram bastante cooperação entre os integrantes das equipes. Acostumados com o método escoteiro, que propõe atividades progressivas e variadas, com jogos técnicos, cooperativos, e em equipe (TOKUDOME; GAY, 2014), os participantes do G3 que não venceram o jogo souberam lidar com a frustração. As crianças se engajaram na atividade, elogiaram as imagens e demonstraram interesse em conhecer mais a respeito das plantas, animais e paisagens ali mostrados.

Para Antunes (2012), embora não haja consenso entre os docentes quanto a atividades que encorajem a competitividade, situações de aprendizagem em que haja competição, sucedidas por outras em que haja cooperação, estimulam no aluno uma percepção mais apurada e contextualizada da realidade. Ambos os aspectos - competição e cooperação - 
foram percebidos nas aplicações do jogo-didático, que teve uma boa aceitação dos participantes do G1 e do G2, de acordo com a pesquisa de opinião.

Uma das questões da pesquisa de opinião, que afirmava "O jogo não foi útil para o aprendizado", teve 51,22\% ( $n=21)$ de respostas "nem um pouco" e 41,46\% ( $n=17)$ de respostas "não", indicando que os respondentes consideraram o jogo útil para o aprendizado e que não responderam de modo automático às questões. Os estudantes responderam, ainda, que gostariam de participar de mais atividades como essa, constatando a aceitabilidade da proposta apresentada.

Os resultados da pesquisa de opinião, apresentados na Tabela 3, demonstram o grande potencial dos jogos para a educação ambiental. A avaliação do jogo-didático pelos sujeitos da pesquisa mostrou-se positiva, constatando ser motivadora para o aprendizado sobre o Cerrado, divertida e capaz de mostrar como o bioma é importante. É preciso ressaltar, contudo, que desafio não reside somente em despertar o interesse do aluno pelo tema, mas, também o do docente.

\begin{tabular}{|c|c|c|c|c|c|}
\hline Afirmações & Nem um pouco & $\begin{array}{c}\text { Não } \\
\vdots \\
\vdots\end{array}$ & $\begin{array}{c}\text { Não sei } \\
\cdots\end{array}$ & Sim & $\begin{array}{c}\text { Com certeza } \\
\cdots\end{array}$ \\
\hline $\begin{array}{c}\text { "O jogo me motivou a } \\
\text { aprender sobre o Cerra- } \\
\text { do" }\end{array}$ & $0 \%$ & $0 \%$ & $4,88 \%(n=2)$ & $\begin{array}{c}21,95 \% \\
(n=9)\end{array}$ & $73,17 \%(n=30)$ \\
\hline $\begin{array}{l}\text { "O jogo foi útil para o } \\
\text { meu aprendizado" }\end{array}$ & $0 \%$ & $0 \%$ & $0 \%$ & $53,66 \%(n=22)$ & $46,34 \%(n=19)$ \\
\hline $\begin{array}{c}\text { "O jogo foi uma maneira } \\
\text { divertida de aumentar } \\
\text { minha compreensão so- } \\
\text { bre o tema" }\end{array}$ & $0 \%$ & $0 \%$ & $0 \%$ & $31,71 \%(n=13)$ & $68,29 \%(n=28)$ \\
\hline $\begin{array}{l}\text { "Com o jogo, conheci ani- } \\
\text { mais que não conhecia" }\end{array}$ & $\begin{array}{c}2,44 \% \\
(n=1)\end{array}$ & $14,63 \%(n=6)$ & $0 \%$ & $36,59 \%(n=15)$ & $46,34 \%(n=19)$ \\
\hline $\begin{array}{c}\text { "O jogo me mostrou } \\
\text { como o Cerrado é impor- } \\
\text { tante" }\end{array}$ & $0 \%$ & $0 \%$ & $0 \%$ & $41,46 \%(n=17)$ & $58,54 \%(n=24)$ \\
\hline $\begin{array}{l}\text { "O jogo NÃO foi útil para } \\
\text { o meu aprendizado" }\end{array}$ & $51,22 \%(n=21)$ & $\begin{array}{c}41,46 \% \\
(n=17)\end{array}$ & $2,44 \%(n=1)$ & $\begin{array}{c}2,44 \% \\
(n=1)\end{array}$ & $\begin{array}{c}2,44 \% \\
(n=1)\end{array}$ \\
\hline $\begin{array}{c}\text { "Eu gostaria de participar } \\
\text { de mais atividades como } \\
\text { essa na escola" }\end{array}$ & $0 \%$ & $0 \%$ & $0 \%$ & $\begin{array}{c}7,32 \% \\
(n=3)\end{array}$ & $92,68 \%(n=38)$ \\
\hline
\end{tabular}

Tabela 3. Resultados do questionário da pesquisa de opinião sobre o jogo Memórias do Cerrado, com a utilização de emoticons e o modelo de escala Likert. Porcentagens referentes à totalidade das respostas do G1 e do G2 (n=41). 
Em pesquisa realizada no Distrito Federal, Bizerril e Faria (2003) constataram que a temática do Cerrado é pouco abordada de forma transversal no ensino fundamental. Os autores revelam que, de acordo com os próprios professores, esse fato pode estar relacionado a lacunas na formação docente e ao tratamento dado ao bioma pela mídia. Assim, metodologias que possibilitem o ensino do Cerrado em diferentes contextos e que ofereçam oportunidade para a interdisciplinaridade podem contribuir para que docentes se proponham a tratar a temática em suas aulas.

Ressalta-se que o quiz do Memórias do Cerrado pode ser elaborado a partir de conteúdos de diversas disciplinas. Em Língua Portuguesa, por exemplo, é possível abordar etimologia e hifenização utilizando termos do Cerrado, como "capivara", do tupi kapii-wára (MICHAELIS, 2015), e "lobo-guará". Em Física, pode-se trabalhar a cinemática por meio do cálculo da velocidade média de um veículo que se choca com um animal em uma estrada. Em Geometria Plana, pode-se propor o cálculo de uma área desmatada. São inúmeras as possibilidades deste jogo-didático, a começar pela opção de incluir ou não o quiz.

As experiências com o G2 e o G3 demonstraram o valor educativo do jogo-didático independentemente da utilização do quiz, apresentando resultados positivos e significativos. Por meio da observação participante dos grupos, notamos que, em geral, os sujeitos permaneceram atentos durante as explanações sobre a fauna e a flora do Cerrado, e demonstraram espanto com o grande número de animais ameaçados de extinção. O interesse e a atenção dos participantes também foram ratificados pelos desenhos realizados no pós-teste, que revelaram não só o acréscimo de elementos apresentados nas cartas, como também de situações comentadas ao longo da partida.

Diante da carta do lobo-guará, por exemplo, explicou-se aos estudantes que essa espécie possui hábito predominantemente solitário, exceto no período reprodutivo. Tal informação levou um participante do G2 a desenhar dois lobos-guarás (Chrysocyon brachyurus) juntos e, ao descrever seu desenho, justificou tratar-se da época do acasalamento (BRASIL, 2018). Em seu pós-teste, apresentado na Figura 4, notamos ainda o acréscimo de outros seis elementos presentes nas cartas: desmatamento, frutos de buriti (Mauritia flexuosa), flores de caliandra (Calliandra dysantha) e de chuveirinho (Paepalanthus chiquitensis), tamanduá-bandeira (Myrmecophaga tridactyla) e tartaruga-da-amazônia (Podocnemis expansa).

Os testes de outro participante do G2, apresentados na Figura 5, também o acréscimo de oito elementos no segundo desenho, dentre eles, representações de uma capivara ( $\mathrm{Hy}^{-}$ drochoerus hydrochaeris) bebendo água em um lago, e outra próximo a um rio. O aluno, que já havia desenhado o lago e o rio no pré-teste, teve a percepção de incluir as capivaras no pós-teste após aprender que em seu habitat há disponibilidade de água (HERRERA; MACDONALD, 1989). Nesse sentido, a utilização do desenho como método de avaliação demonstrou estimular o raciocínio e a criatividade dos sujeitos. 


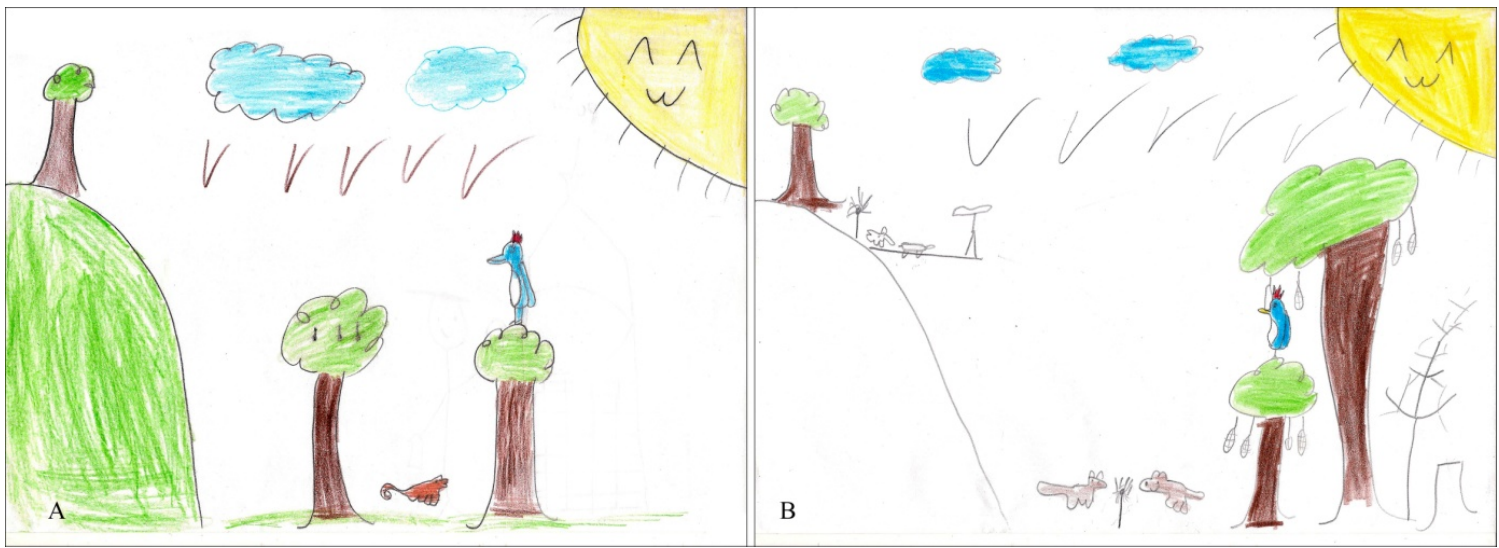

Figura 4. Pré-teste e Pós-teste com desenhos realizados por estudante com 13 anos de idade, matriculado no $7^{\circ}$ ano em uma escola estadual em Aparecida de Goiânia-GO. A) Pré-teste: representação de paisagem do Cerrado com árvores, pássaros, nuvens, morro, sol, pica-pau e macaco. B) Pós-teste: representação de mesma paisagem com acréscimo de um mirante sobre o morro e sete elementos apresentados no jogo-didático - desmatamento, frutos de buriti (Mauritia flexuosa), flores de caliandra (Calliandra dysantha) e chuveirinho (Paepalanthus chiquitensis), tamanduá-bandeira (Myrmecophaga tridactyla), tartaruga-da-amazônia (Podocnemis expansa) e lobosguará (Chrysocyon brachyurus).

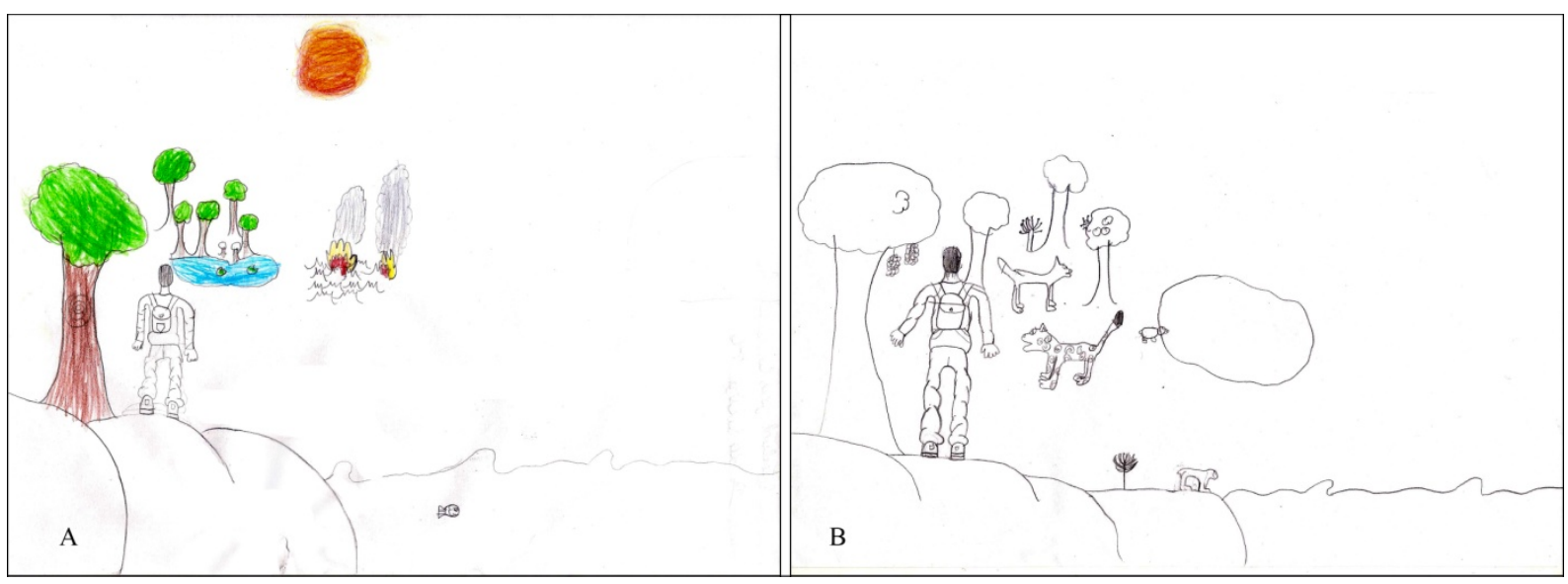

Figura 5. Pré-teste e Pós-teste com desenhos realizados por estudante com 12 anos de idade, matriculado no $7^{\circ}$ ano em uma escola estadual em Aparecida de Goiânia-GO. A) Pré-teste: representação de paisagem do Cerrado com árvores, sol, lago, rio, peixe, figura humana e queimada. B) Pós-teste: representação da mesma paisagem com o acréscimo de frutos de buriti (Mauritia flexuosa) e de pequi (Caryocar brasiliense), flores de caliandra (Calliandra dysantha) e de chuveirinho (Paepalanthus chiquitensis), onça-pintada (Panthera onca), lobo-guará (Chrysocyon brachyurus) e capivaras (Hydrochoerus hydrochaeris) posicionadas próximo ao lago e ao rio. O desenho não foi colorido devido ao limite do tempo.

\section{CONCLUSÃO}

As experiências de aplicação e avaliação do jogo-didático Memórias do Cerrado demonstraram haver equilíbrio entre seu teor educativo e de ludicidade. Com ótima aceitabilidade pelos sujeitos, que se entusiasmaram com a atividade, a proposta pode contribuir 
para o processo de ensino-aprendizagem em diferentes contextos e ambientes voltados para faixas etárias variadas. Trata-se de uma estratégia de ensino diferenciada que, conforme pontuou a revisão da literatura realizada neste estudo, pode contribuir para o ensino sobre o bioma, bem como para atitudes positivas em relação à sua conservação.

Destaca-se, ainda, que as regras do jogo se mostraram de fácil entendimento e tampouco há complexidade na confecção das peças e elaboração do quiz, o que favorece sua reprodutibilidade e utilização pelos docentes. Além disso, seu formato possibilita a utilização de outras temáticas e assuntos nas imagens das cartas ou no quiz, favorecendo a interdisciplinaridade. Pode ser necessário, contudo, que seja reduzida a quantidade de cartas, pois a aplicação do jogo demandou um tempo maior do que o de uma aula convencional, sendo necessária a utilização de dois tempos de aula.

O uso do jogo de memória e do quiz e os resultados positivos em relação ao aprendizado e aceitabilidade não esgotam as possibilidades de abordagem educacional e lúdica sobre o bioma. Na verdade, as atividades realizadas abrem possibilidades para a criação e o uso de novos jogos, bem como a realização de adequações aos diferentes contextos e públicos. Por fim, a baixa frequência de publicações voltadas para recursos didáticos para o ensino sobre o Cerrado reforçaa a necessidade de mais estudos, de mais ferramentas educacionais acessíveis e do compartilhamento das experiências exitosas, visando a aprendizagem, valorização e conservação do bioma Cerrado.

\section{REFERENCIAS}

AMARAL, D. F. et ai. Percepção sobre o Bioma Cerrado (Goiás, Brasil) de Estudantes do Ensino Médio de Escolas da Educação Básica. Revista Portuguesa de Estudos Regionais, [s.l.], v. 1, n. 45, p. 71-82, jan. 2017. Disponível em: https://www.redalyc.org/ pdf/5143/514354 170 004.pdf. Acesso em: 9 fev. 2020.

ANGELINI R. et al. Effect of outdoor and laboratorial environment science activities on middle school students understanding on conservation. Nature \& Conservation, v. 9, n.1, p. 1-5, 2011. DOI: http://doi.editoracubo.com.br/10.4322/natcon.2011.012

ANTUNES, C. Professores e Professauros: reflexões sobre a aula e práticas pedagógicas diversas. Petrópolis: Vozes, 2012. 205 p. ISBN: 9788532644 299, edição digital.

ARRUDA, A. F. D. S.; FARIAS, M. E.; GARBOUJ, M. Weaving Teaching Situations in Environmental Education Seeking Sustainability in the Cerrado. Acta Scientiae: Revista de Ensino de Ciências e Matemática, [s.l.], v. 20, n. 6, p. 1028-1042, 10 dez. 2018. Galoa Events Proceedings. DOI: http://dx.doi.org/10.17648/acta.scientiae.v20iss6id4799.

BARBOSA, F. F. Biodiversidade do Cerrado no ensino de Ciências: uma sequência didática com abordagem sobre insetos. 2018. 76 f. Dissertação (Mestrado) - Curso de Mestrado Profissional em Ensino de Ciências, Universidade Estadual de Goiás, Anápolis, 
2018. Disponível em: https://www.bdtd.ueg.br/bitstream/tede/124/2/Disserta \%C3\%A7\%C3\%A3o_CD.pdf. Acesso em: 5 abr. 2019.

BELINASO, L.; ESTEVINHO, L.; RAMOS, M. B. Environmental education in television narratives: a brazilian case study. Environmental Education Research, [s.l.], v. 24, n. 10, p. 1490-1500, 3 out. 2018. Informa UK Limited. DOI: http://dx.doi.org/ 10.1080/13504622.2018.1545150.

BEZERRA, R. G.; NASCIMENTO, L. M. C. T. Concepções do bioma Cerrado apresentadas por estudantes do ensino fundamental de Formosa - Goiás. Cadernos de Educação, Tecnologia e Sociedade, [s.l.], v. 8, n. 1, p. 8-21, 21 abr. 2015. Brazilian Journal of Education, Technology and Society (BRAJETS). DOI: http://dx.doi.org/10.14571/ cets.v8i1.230.

BEZERRA, R. G.; SUESS, R. C. Abordagem do bioma Cerrado em livros didáticos de Biologia do ensino médio. Holos, [s.l.], v. 1, p. 233-242, 17 mar. 2013. Instituto Federal de Educação, Ciência e Tecnologia do Rio Grande do Norte (IFRN). DOI: http://dx.doi.org/10.15628/holos.2013.1289.

BIZERRIL, M. X. A.; FARIA, D. S. A Escola e a Conservação do Cerrado: uma análise no ensino fundamental do distrito federal. Revista Eletrônica do Mestrado em Educação Ambiental, Brasília, v. 10, p. 19-31, jan. 2003. Disponível em: https://www.agencia.cnptia.embrapa.br/recursos/Conservacao_Cerrado_Escola_DFID-DSAZU04Loa.pdf.

Acesso em: 15 abr. 2019.

BIZERRIL, M. X. A. O Cerrado nos livros didáticos de geografia e ciências. Ciência Hoje, [s.l.], v. 32, n.192, p.56-60, 2003. Disponível em: https://www.researchgate.net/publication/259467083_O_Cerrado_nos_livros_didaticos_de_geografia_e_ciencias. Acesso em: 20 fev. 2020.

BIZERRIL, M. X. A. Children's Perceptions of Brazilian Cerrado Landscapes and Biodiversity. The Journal Of Environmental Education, [s.l.], v. 35, n. 4, p. 47-58, jul. 2004. Informa UK Limited. Disponível em: http://dx.doi.org/10.3200/joee.35.4.47-58. Acesso em: 15 abr. 2019.

BORGES, S. H. A importância do ensino de pós-graduação na formação de recursos humanos para o estudo da biodiversidade no Brasil: um estudo de caso na ornitologia. Biota Neotropica, [s.l.], v. 8, n. 1, p. 21-27, jan. 2008. Disponível em: https:// www.biotaneotropica.org.br/v8n1/pt/abstract?point-of-view+bn00 108012 008. Acesso em: 15 abr. 2019.

BORGES, P. S.; SIMIÃO-FERREIRA, J. S. Percepção ambiental dos alunos do ensino fundamental sobre a biodiversidade de Cerrado. Revista Ciências \& Ideias, [s.l.], v. 9, n. 1, p. 1, 15 ago. 2018. Instituto Federal de Educaçãoao Ciência e Tecnologia do Rio de Janeiro - IFRJ. http://dx.doi.org/10.22407/2176-1477/2018.v9i1.640.

BRANDO, F. R. Proposta didática para o ensino médio de Biologia: as relações ecológicas no cerrado. 2010. 217 f. Tese (Doutorado em Educação para a Ciência) - Universi- 
dade Estadual Paulista, Bauru, 2010. Disponível em: https://repositorio.unesp.br/handle/11449/102 036. Acesso em: 12 abr. 2019.

BRASIL. Secretaria de Educação Básica. Base Nacional Comum Curricular. Brasília: MEC/Secretaria de Educação Básica, 2017. Disponível em: http://basenacionalcomum.mec.gov.br/images/BNCC_EI_EF_110518_versaofinal_site.pdf. Acesso em: 12 abr. 2019.

BRASIL. Instituto Chico Mendes de Conservação da Biodiversidade. Ministério do Meio Ambiente (org.). Livro Vermelho da Fauna Brasileira Ameaçada de Extinção: volume ii - mamíferos. Brasília: ICMBio/MMA, 2018. Disponível em: https://www.icmbio.gov.br/portal/images/stories/comunicacao/publicacoes/publicacoes-diversas/livro_vermelho_2018_vol2.pdf. Acesso em: 5 abr. 2019.

BRASIL. Instituto Brasileiro de Geografia e Estatística. Ministério da Economia (ed.). Biomas e sistema costeiro-marinho do Brasil: compatível com a escala 1:250 000. Rio de Janeiro: IBGE, Coordenação de Recursos Naturais e Estudos Ambientais, 2019. 164 p. (Relatórios metodológicos). v. 45. Disponível em: https://biblioteca.ibge.gov.br/ index.php/biblioteca-catalogo?view=detalhes\&id=2 101676. Acesso em: 3 jan. 2020.

CASTRO, F. G. et al. A Methodology for Conducting Integrative Mixed Methods Research and Data Analyses. Journal Of Mixed Methods Research, [s.l.], v. 4, n. 4, p. 342-360, 20 set. 2010. SAGE Publications. DOI: http://dx.doi.org/ $10.1177 / 1558689810382916$.

CASTRO, S. C. P. Mapeamento Ambiental Como Proposta Para a Construção dos Conceitos de Biodiversidade e Cerrado no Ensino Ensino de Biologia. 2009. 108 f. Dissertação (Mestrado) - Curso de Mestrado em Educação em Ciências e Matemática, Universidade Federal de Goiás, Goiânia, 2009. Disponível em: http:// repositorio.bc.ufg.br/tede/handle/tde/586. Acesso em: 2 maio 2019.

CAZOTO, J. L.; TOZONI-REIS, M. F. C. Construção coletiva de uma trilha ecológica no cerrado: pesquisa participativa em educação ambiental. Ciência \& Educação (Bauru), [s.l.], v. 14, n. 3, p. 575-582, jan. 2008. FapUNIFESP (SciELO). DOI: http://dx.doi.org/ 10.1590/s1516-73132008000300013.

COSTA, T. B. et al. A visão do bioma Cerrado no Ensino Fundamental do município de Goiânia e sua relação com os livros didáticos utilizados como instrumento de ensino. Revista Polyphonía, [s.l.], v. 21, n. 1, p. 337, 2011. DOI: http://dx.doi.org/ 10.5216/rp.v21i1.16307.

CRESWELL, J. W. Projeto de pesquisa: métodos qualitativos, quantitativos e mistos. 2. ed. Porto Alegre: Artmed, 2007. 248 p.

ESCOTEIROS DO BRASIL. Organização Mundial do Movimento Escoteiro. 2019. Disponível em: https://www.escoteiros.org.br/mundo/. Acesso em: 10 abr. 2019. 
EZZIYYANI, M. Advanced Intelligent Systems for Sustainable Development. Marrocos: Springer, 2019. 407 p. http://dx.doi.org/10.1007/978-3-030-36 664-3

FALEIRO, F. A. et al. Metodologias educacionais diversificadas como proposta de socialização da educação ambiental e ensino da Biologia da flora do Cerrado. Enciclopédia Biosfera, [s. l.], v. 5, n. 08, 2009. Disponível em: https://conhecer.org.br/ojs/ index.php/biosfera/article/view/4796. Acesso em: 3 abr. 2019.

FRANCELIN, L. P. O saber-fazer dos professores de geografia do ensino fundamental: fatores que poderão influenciar na escolha dos procedimentos didáticos para ensinar sobre o cerrado. 2011. 144 f. Dissertação (Mestrado em Educação Para A Ciência) - Universidade Estadual Paulista, Bauru, 2011. Disponível em: https:// repositorio.unesp.br/handle/11449/90 982?locale-attribute=es. Acesso em: 12 abr. 2019.

FRANÇA, L. R. Epistemologia e ensino de biogeografia, análises de livros didáticos e práticas pedagógicas para o estudo e conscientização sobre o cerrado brasileiro. 2019. 195 f. Dissertação (Mestrado) - Curso de Mestrado em Geografia, Universidade Federal de Uberlândia, Uberlândia, 2019. Disponível em: http://dx.doi.org/10.14393/ ufu.di.2019.684. Acesso em: 5 maio 2019.

GERHARDT, T. E.; SILVEIRA, D. T (org.). Métodos de Pesquisa. Porto Alegre: UFRGS, 2009. 120 p. (EAD Educação a Distância). Disponível em: http://www.ufrgs.br/cursopgdr/downloadsSerie/derad005.pdf. Acesso em: 5 fev. 2019

GIL, A. C. Como elaborar projetos de pesquisa. 4. ed. São Paulo: Atlas, 2002. 175 p.

GOHN, M. G. Educação Não-Formal e o Papel do Educador (a) Social. Revista Meta: Avaliação, [s.l.], v. 1, n. 1, p. 28, 9 jun. 2009. Revista Meta - Avaliação. http://dx.doi.org/10.22347/2175-2753v1i1.1.

GOLDBERG, L. G.; YUNES, M. A. M.; FREITAS, J. V. D. O desenho infantil na ótica da ecologia do desenvolvimento humano. Psicologia em Estudo, [s.l.], v. 10, n. 1, p. 1-10, abr. 2005. FapUNIFESP (SciELO). http://dx.doi.org/10.1590/s141373722005000100012 .

GOLEMAN, D. Emotional Intelligence: why it can matter more than IQ. New York: Bantam Books, 1995. Print.

GONÇALVES, F. P. Estudo das representações sociais do cerrado na visão de alunos do ensino fundamental de escolas rurais em Rio Verde-GO. 2015. 146 f. Dissertação (Mestrado em Geografia) - Universidade Federal de Goiás, Jataí, 2015.

GUIMARÃES, A.; RODRIGUES, A. S. L.; MALAFAIA, G. Adequação de um protocolo de avaliação rápida de rios para ser usado por estudantes do ensino fundamental. Ambiente e Água - An Interdisciplinary Journal Of Applied Science, [s.l.], v. 7, n. 3, p. 241-260, 31 dez. 2012. Instituto de Pesquisas Ambientais em Bacias Hidrograficas (IPABHi). http://dx.doi.org/10.4136/ambi-agua.996. 
HAYDT, R. C. C. Curso de Didática Geral. São Paulo: Ática, 2011. 246 p. (Educação em Ação). Livro digital.

HERRERA, E. A; MACDONALD, D. W. Resource utilization and territoriality in groupliving capybaras (Hydrochoerus hydrochaeris). Journal Of Animal Ecology, London, v. 58, n. 2, p. 667-679, jun. 1989.

IARED, V. G.; OLIVEIRA, H. T.; REID, A. Aesthetic experiences in the Cerrado (Brazilian savanna): contributions to environmental education practice and research. Environmental Education Research, [s.l.], v. 23, n. 9, p. 1273-1290, 24 abr. 2017. Informa UK Limited. http://dx.doi.org/10.1080/13504 622.2017.1312290.

JARMAN, R. Science learning through scouting: an understudied context

for informal science education. International Journal of Science Education, 27:4, 427-450, http://dx.doi.org/10.1080/0 950069042000266182.

KANDA, C. Z. et al. Trilha sensitiva como estratégia de ensino do bioma Cerrado. Revista Brasileira de Educação Ambiental (Revbea), [s.l.], v. 9, n. 1, p. 23-36, 16 jul. 2014. Universidade Federal de São Paulo. http://dx.doi.org/10.34024/revbea.2014.v9.1801.

KATO, D. S; KAWASAKI, C. S. As concepções de contextualização do ensino em documentos curriculares oficiais e de professores de ciências. Ciência \& Educação, [s.l.], v. 17, n. 1, p. 35-50, 2011. http://dx.doi.org/10.1590/s1516-7 3132011000100003.

LEVINE, H. G. et al. Teaching Participant-Observation Research Methods: a skills-building approach. Anthropology \& Education Quarterly, [s.l.], v. 11, n. 1, p. 38-54, mar. 1980. Wiley. http://dx.doi.org/10.1525/aeq.1980.11.1.05x1849c.

LIKERT, R. A technique for the measurement of attitudes. Archives of Psychology (New York), v. 22, p. 5-55, 1932-33.

MALONE, T. W.; LEPPER, M. R. Making learning fun: a taxonomy of intrinsic motivations for learning. In: SNOW, R. E.; FARR, M. J (org.). Aptitude, learning and instruction: conative and affective process analyses. London: Lawrence Erlbaum Associates, 1987. Cap. 10. p. 223-252.

MARTINS, C. O.; BRANDO, F. R. Levantamento de concepções de alunos do ensino médio sobre o Cerrado e suas implicações para o ensino. In: ENCONTRO NACIONAL DE PESQUISA EM EDUCAÇÃO EM CIÊNCIAS, 7., 2009, Florianópolis. Anais[...]. Florianópolis: ABRAPEC, 2009.

MICHAELIS. Michaelis: Dicionário Brasileiro da Língua Portuguesa. 2015. ISBN: 978-8506-04 024-9. Disponível em: https://michaelis.uol.com.br/moderno-portugues/busca/ portugues-brasileiro/capivara/. Acesso em: 5 jun. 2020. 
MITTERMEIER, R. A.; MYERS, N.; MITTERMEIER, C. G. (ed.). Hotspots: earth's biologically richest and most endangered terrestrial ecoregions. Mexico City: Cemex S. A., Agrupación Sierra Madre, S. C., 1999. 430p.

MOTTA, A. C. O. O bioma Cerrado no ensino médio: percepção de alunos, professores e abordagem do Exame Nacional do Ensino Médio (Enem). 2021. 99f. Dissertação (Mestrado) - Curso de Mestrado Profissional em Ensino para a Educação Básica, Urutaí, 2021. Disponível em: https://repositorio.ifgoiano.edu.br/bitstream/prefix/1902/1/DISSERTA\%C3\%87\%C3\%83O\%20ANA\%20CAROLINA\%20DE\%20OLIVEIRA\%20MOTTA \%20.pdf. Acesso em: 4 nov. 2021.

NETO, J. O. R.; SOUZA, D. J. A natureza como ferramenta de ensino: uma análise interdisciplinar do Instituto de Permacultura e Ecovilas do Cerrado. Revista Científica de Educação, Inhumas, v. 2, n. 1, p. 60-72, jan. 2017. Disponível em: https://seer.facmais.edu.br/rc/index.php/RCE/article/view/24/18. Acesso em: 6 abr. 2019.

OLIVEIRA, I. F. Materiais sobre o cerrado: desafios e contribuições para o ensino formal do bioma sob perspectiva da educação ambiental crítica. 2014. 131 f. Dissertação (Mestrado Profissional em Ensino de Ciências)-Universidade de Brasília, Brasília, 2014.

OLIVEIRA, S. R. L.. Formação do conceito de cerrado e o ensino de geografia: análise dos conhecimentos geográficos de alunos do ensino médio da rede pública estadual de Jataí/Goiás. 2012. 107 f. Dissertação (Mestrado) - Curso de Mestrado em Geografia, Universidade Federal de Goiás, Jataí, 2012. Disponível em: https:// posgeo.jatai.ufg.br/p/21 939-suzana-ribeiro-lima-oliveira. Acesso em: 10 abr. 2019.

PALHACI, T. P. et al. Caracterização do bioma Cerrado por alunos de ensino médio. In: Encontro Nacional de Pesquisa em Educação de Ciências, 7., 2009, Florianópolis. Anais [...]. Florianópolis: ABRAPEC, 2009. p. 1-12. Disponível em: https://www.yumpu.com/pt/document/read/13 026378/caracterizacao-do-bioma-cerrado-por-alunos-de-ensino-medio. Acesso em: 15 jun. 2019.

PINTO, L. C. L.; MATEUS, M. B.; PIRES, M. R. S. Conhecimentos e usos da fauna terrestre por moradores rurais da Serra do Ouro Branco, Minas Gerais, Brasil. Interciência, [s. l.], v. 37, n. 7, p. 520-527, jul. 2012. Disponível em: https://www.interciencia.net/ wp-content/uploads/2018/01/520-c-1\%C2\%BA-PINTO-8.pdf. Acesso em: 15 jun. 2019.

QUEIROZ, H. P. R.; PEREIRA, S. G.; BORGES, D. C. S. A Conscientização dos Alunos do Ensino Fundamental para a Preservação do Cerrado. Revista Brasileira de Educação e Cultura, São Gotardo, v. 1, n. 8, p. 01-16, 2013.

RISSI, M.N.; CAVASSAN, O. Uma proposta de material didático baseado nas espécies de Vochysiaceae existentes em uma trilha no cerrado de Bauru-SP. Biota Neotropica, v. 13, n. 1, 2013, p. 26-41 Instituto Virtual da Biodiversidade, Campinas. Disponível em: http://www.biotaneotropica.org.br/v13n1/en/ abstract?article+bn00 213012013 . Acesso em: 15 jun. 2019. 
RODRIGUES, L. F. S. A inserção do bioma cerrado no conteúdo de botânica do ensino médio a partir das concepções prévias do aprendiz. 2019. $104 \mathrm{f}$. Dissertação (Mestrado em Educação em Ciências e Matemática) - Universidade Federal de Goiás, Goiânia, 2019. Disponível em: http://repositorio.bc.ufg.br/tede/handle/tede/9386. Acesso em: 5 abr. 2019.

ROSA, R. G. Do big bang ao cerrado atual: interdisciplinaridade no ensino de ciências integrando espaços não formais. 2015. 79 f. Dissertação (Mestrado em Educação em Ciências e Matemática) - Universidade Federal de Goiás, Goiânia, 2015. Disponível em: https://repositorio.bc.ufg.br/tede/handle/tede/4840. Acesso em: 10 abr. 2019.

SAMPAIO, R. F.; MANCINI, M. C. Estudos de revisão sistemática: um guia para síntese criteriosa da evidência científica. Revista Brasileira de Fisioterapia, [s.l.], v. 11, n. 1, p. 83-89, fev. 2007. FapUNIFESP (SciELO). http://dx.doi.org/10.1590/s141335552007000100013 . Disponível em: https://www.scielo.br/scielo.php?script=sci_arttext\&pid=S1413-3 5552007000100 013. Acesso em: 6 abr. 2019.

SANTOS, A. V. S. Percepção dos Discentes de Escolas de Ensino Médio Sobre os Impactos Ambientais no Cerrado, no Município de Chapadinha-MA. 2017. $37 \mathrm{f}$. TCC (Graduação em Ciências Biológicas) - Universidade Federal do Maranhão, Chapadinha, 2017. Disponível em: http://hdl.handle.net/123 456 789/1447. Acesso em: 10 abr. 2019.

SENICIATO, T.; CAVASSAN, O. O ensino de ecologia e a experiência estética no ambiente natural: considerações preliminares. Ciência \& Educação, Bauru, v. 15, n. 2, p. 393-412, jan. 2009. FapUNIFESP (SciELO). http://dx.doi.org/10.1590/s151673132009000200010 .

TEIXEIRA, P. M. M.; NETO, J. M. O estado da arte da pesquisa em ensino de Biologia no Brasil: um panorama baseado na análise de dissertações e teses. Revista Electrónica de Enseñanza de las Ciencias, v. 11, n. 2, p. 273-297, 2012. Disponível em: http://reec.uvigo.es/volumenes/volumen11/REEC_11_2_2_ex500.pdf. Acesso em: 15 abr. 2019.

TOKUDOME, M.; GAY, V. A (org,). Apostila do Cursante: curso básico. 2. ed. Curitiba: Escoteiros do Brasil, 2014. (Linha Escotista). Disponível em: https://www.escoteiros.org.br/wp-content/uploads/2016/06/Curso_b\%C3\%A1sico_escotista_cursante.pdf. Acesso em: 10 jun. 2019.

VALLERIUS, D. M. E que tal o Cerrado, professor? Algumas reflexões sobre a construção de uma consciência de Cerrado no ensino básico. Revista Interface, [s. l.], v. 1, n. 9, p. 147-158, jun. 2015. Disponível em: sistemas.uft.edu.br. Acesso em: 2 abr. 2019.

VELLEMAN, D. J.; WARRINGTON, G. S. What to Expect in a Game of Memory. The American Mathematical Monthly, [s.l.], v. 120, n. 9, p. 787, 2013. Informa UK Limited. http://dx.doi.org/10.4169/amer.math.monthly.120.09.787. 